\section{Japanese doctors keep quiet}

Tokyo

IN A precedent-setting court case, a Nagoya judge last week ruled that Japanese doctors are not obliged to tell patients suffering from terminal cancer the true nature of their condition. "Informed consent", the notion that a patient has a right to know before giving consent for treatment, has yet to win recognition in Japan.

The case involved Kazuko Makino, a 50-year-old woman. She went to Nagoya Red Cross Hospital in January 1983 where she was told she was suffering from gallstones, although the hospital doctor suspected gall-bladder cancer. The doctor recommended surgery, but Makino, a nurse, knew that gallstones are not lifethreatening and decided against the operation. By June 1983 the cancer had spread to her liver and in December she died.

Her husband and family filed a malpractice suit against the hospital for failing to inform Makino of the true nature of her illness. But in last week's district court ruling, the judge rejected the suit concluding that Makino alone was responsible for her decision to reject surgery. Judge Kuniharu Ito ruled that although it is a doctor's duty to "explain accurately and concretely about the sickness to the patient" it is up to the doctor to decide to whom, when, what and how much to explain because such disclosure can affect the recovery of the patient

Makino's case is not exceptional. As a general rule, doctors in Japan do not tell patients if they have cancer. In a survey of several hundred doctors by the Mainichi newspaper in 1987 , nearly 80 per cent of doctors said that the patient should not be told. Even the late emperor was not told he had pancreatic cancer. And some doctors do not inform AIDS patients of the true nature of their condition.

The Mainichi survey revealed that doctors believe that their patients will not be able to cope with the truth and that telling them they have cancer will only hasten their demise. But also behind the silence lies the Japanese deference for authority. Patients tend to accept the diagnosis and treatment of their doctors without question. The Makino family is exceptional in taking their doctor to court.

The need to conceal the true nature of a cancer patient's condition also helps to explain a peculiar feature of drug sales in Japan. Unlike the United States and Europe, where anti-ulcer drugs and treatments for hypertension are the biggest sellers, Japan's pharmaceutical market is dominated by Krestin, an anti-cancer agent marketed by Sankyo Pharmaceuticals. Krestin, an extract of a tree fungus, has annual sales in Japan of around $\$ 400$ million. But it is not sold anywhere else in the world. And despite its phenomenal popularity, there are real doubts as to its efficacy.

According to Masanori Fukushima, head of the department of internal medicine at Aichi Cancer Centre, there is no conclusive evidence that Krestin prolongs the life of cancer patients. A spokesman for Kureha Chemical Industry, the company which developed Krestin, agrees that mortality of the patients was not examined.

Krestin's advantages are that it is taken in a convenient oral form and has no sideeffects, causing none of the tell-tale symptoms, such as hair loss, of other anticancer therapies. Thus patients given Krestin can remain unaware they are being treated for cancer. And doctors who prescribe Krestin can ease their conscience by knowing they have at least prescribed something.

But times are changing. A recent report from Prudential-Bache Securities refers to Krestin as an "embarrassment to the Japanese medical community" and says that in the future Japanese patients and doctors can be expected "to cooperate in fighting cancer as they do in Western society now". Krestin, which was approved for marketing in the late 1970s, is being re-evaluated by the Ministry of Health and Welfare. David Swinbanks

\section{False-colour Dawn}

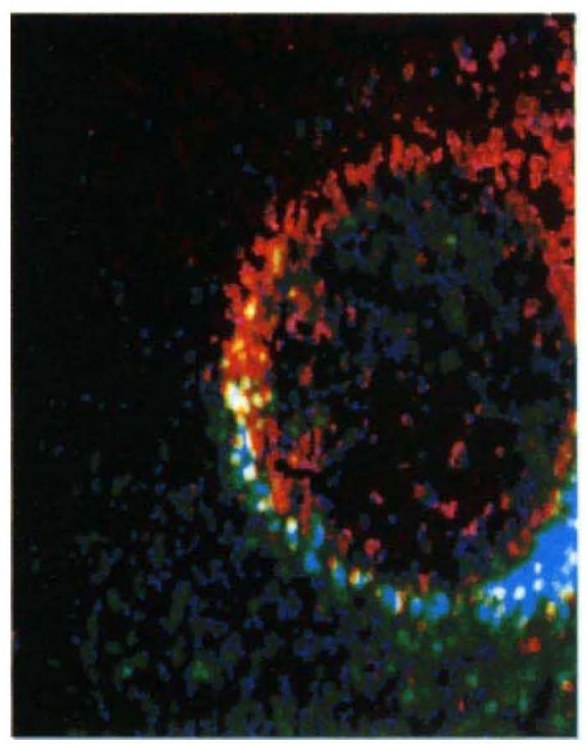

JAPAN's satellite Akebono (Dawn) snapped this picture of the aurora australis from an altitude of 7,500 kilometres over the South Pole on 27 April. The falsecolour ultraviolet image spans a distance of about 4,000 kilometres and the exposure time was 0.6 seconds. Akebono was launched in February by the Institute of Space and Astronautical Science (Nature 338, 8;2 March 1989).

\section{Space plane spawns hypersonic plans}

\section{Bonn}

A GRANTING committee of the Deutsche Forschungsgemeinschaft (DFG) is expected to overcome its initial misgivings and approve today two "special collaborative programmes" for research into hypersonic technologies. The DFG will invest about DM8.2 million in the three years beginning in July 1989 to recreate a West German presence in a research area that the country abandoned 15 years earlier. Two further programmes in the field are expected to be proposed by groups in Braunschweig and Stuttgart and evaluated in the summer of 1990.

The influential science council (Wissenschaftsrat) has already approved the programmes, as has a DFG committee. All that is needed is the formal approval of the special collaborative programmes granting committee, which are expected to be given on 8 June.

Both special collaborative programmes will help to train young engineers in the field of aerospace plane development. Their expertise will be needed to realize West Germany's ambitious plans to build an aerospace plane called Sänger (see Nature 338, 105; 9 March 1989).

Three faculties in the Technical University of Aachen will investigate the feasibility and economy of various conceptions of an aerospace plane. Groups of researchers at the Technical University of Munich, at the University of the Bundeswehr (armed forces) and at the German Aerospace Research Establishment (called DLR in German) will investigate the complex physical-chemical processes involved in hypersonic engine design.

The Research Ministry plans to spend DM220 million over the next four years on developing Sänger, with DLR contributing an additional DM85 million and private industry as much as DM30 million. Sänger could be used for both cargo transport into space and cargo or passenger transport from point to point on Earth.

A decision is expected by 1993 on whether European efforts will focus on Sänger or whether Europe will instead choose competitive planes from Britain or France. A negative decision could mean the abandonment of the project.

Opposition to the project continues from those in the physics community, especially from those who doubt that the popularity at present enjoyed by space research will yield significant long-term results. Even the Wissenschaftsrat "regrets" that there is not more coordination of research plans than is provided by these two programmes. The Wissenschaftsrat also warns that other areas of research such as orbital systems must not be neglected despite the emphasis on hypersonics.

Steven Dickman 